\title{
Trauma Okular oleh Serangan Kerbau - Laporan Kasus
}

\section{Wenny Supit}

Bagian Ilmu Penyakit Mata Fakultas Kedokteran Universitas Sam Ratulangi, Manado, Indonesia

Email: wennysupit@gmail.com

\begin{abstract}
Of the many ocular blunt traumas, trauma due to typical buffalo attack thrrough leverage has not been reported. We reported a 65 -year-old man attacked by a buffalo on his left eye. The patients complained of pain of his left eye associated with swelling, bleeding, and blurred vision. Eye examination revealed that visual acuity of the left eye was classified as hand motion (HM), limited ocular motility, blepharospasm, and a crescent-shaped anterior lamella laceration with lateral canthal involvement. Anterior segment examination revealed bullous subconjunctival hemorrhage, corneal edema, and rosette-shaped opacification (RSO) of the lens. Head-CT showed traumatic cataract and periorbital haemorrhage; no abnormalities in the right eye. Ovular trauma score (OTS) of the patient was three indicating that the possible visual prognosis was $2 \%$ as no light perception (NLP), $11 \%$ as light perception (LP) or hand motion (HM), 15\% as 1/200-19/200, $31 \%$ as $20 / 200-20 / 50$, and $41 \%$ as $>20 / 40$. Literature data showed that the visual sensitivity of OTS prediction in NLP, 20/200-20/50, and 20/40 was $100 \%$. The specificity of OTS in predicting vision in LP/HM 1/200-19/200 was $100 \%$. After a recovery period of approximately two months and the sutured wound healed, the patient came to the eye clinic of Prof. Dr. R. D. Kandou Hospital Manado. After a cataract surgery was performed on the left eye of the patient, his visual acuity improved to 20/40.
\end{abstract}

Keywords: ocular trauma, buffalo attack, ocular trauma score (OTS)

\begin{abstract}
Abstrak: Dari sekian banyaknya trauma tumpul, trauma akibat rudapaksa tipikal serangan kerbau yang menggunakan gaya ungkit belum pernah dilaporkan. Kami melaorkan seorang laki-laki berusia 65 tahun yang mendapat serangan kerbau pada mata kiri dengan keluhan nyeri disertai pembengkakan, pendarahan, dan penglihatan kabur. Pemeriksaan mata menunjukkan ketajaman visual mata kiri dengan gerakan tangan, motilitas okular terbatas, blefarospasme, dan laserasi lamela anterior berbentuk bulan sabit dengan keterlibatan kantal lateral. Pemeriksaan segmen anterior menunjukkan perdarahan subkonjungtiva bulosa, edema kornea, dan rosette-shaped opacification (RSO) pada lensa. Hasil CT-kepala menunjukkan katarak traumatik dan perdarahan periorbital, tanpa kelainan pada mata kanan. Skor trauma okular pasien (OTS) ialah tiga yang menandakan kemungkinan prognosis pada visual pasien ialah $2 \%$ menjadi no light perception (NLP), 11\% menjadi light perception (LP) atau hand motion (HM), 15\% menjadi 1/200-19/200, $31 \%$ menjadi 20/200-20/50, dan 41\% menjadi >20/40. Penggunaan OTS pada kasus ini karena data literatur menunjukkan bahwa sensitivitas penglihatan prediksi OTS di NLP, 20/200-20/50, dan 20/40 ialah $100 \%$. Kekhususan OTS dalam memrediksi visi di LP/HM 1/200-19/200 ialah $100 \%$. Setelah masa pemulihan sekitar dua bulan dan luka penjahitan sembuh, pasien datang kontrol ke poliklinik mata RSUP Prof. Dr. R. D. Kandou Manado. Setelah dilakukan operasi katarak pada mata kiri didapatkan tajam penglihatan mata kiri pasien 20/40.
\end{abstract}

Kata kunci: trauma mata, serangan kerbau, ocular trauma score (OTS)

\section{PENDAHULUAN}

Trauma pada mata sering menyebabkan kesukaran dalam menilai kerusakan yang diakibatkannya. Kadang-kadang pukulan mempunyai kesan tidak keras dan kerusakan matapun sepintas lalu tidak nampak tetapi 
ternyata berakibat berat bahkan sampai terjadi kebutaan. Memang keadaan ini sering mengherankan terutama bagi para sejawat bukan dokter mata oleh karena tidak mempunyai perlengkapan atau perhatian yang cukup untuk menemukan kerusakan yang diakibatkannya. Bahkan bagi dokter mata sendiri kadang-kadang mengalami kesulitan atau tidak menduga adanya kelainan yang dapat membawa kebutaan.

Secara prevalensi pada trauma mata dapat dit-mukan sebesar $47,5 \%$ adanya luka memar pada mata. Sebesar $50,1 \%$ jenis trauma mata nerupakan luka tembus mata. Penetrasi melalui kornea ialah yang paling umum $58,9 \%$, lebih dari setengah pasien tersebut juga memiliki katarak traumatik. Pasien dengan perforasi kornea tanpa katarak dirawat dengan sedikit kesulitan dan sekitar 29\% diikuti dengan luka skleral. Terdapat 22\% mengalami perforasi kornea dan sklera secara bersamaan, disertai luka limbus. Pada sebagian besar kasus dengan perforasi kornea, terdapat juga prolaps vitreous, dan dengan perforasi kornea dan skleral - prolaps jaringan uveal dan vitreous. Dari semua luka tembus bola mata, sebanyak 31,5\% ditemukan adanya benda asing intraokular yang tertahan. Sifat benda asing yang berbeda-beda: yang tersering ialah besi, tetapi juga ditemukan tembaga, perunggu, kayu, plastik, dan kaca. Dari sekian banyaknya trauma tumpul, trauma akibat rudapaksa tipikal serangan kerbau yang menggunakan gaya ungkitan masih belum pernah dilaporkan. ${ }^{1-4}$

Dengan mencermati latar belakang yang disajikan dapat dipahami bahwa trauma mata sangat bervariasi tetapi memiliki pola serupa. Pemahaman keadaan tersebut akan membawa kepada diagnosis dan manajemen cepat-tepat, yang merupakan kunci utama keberhasilan penatalaksanaan kasus trauma mata. Berdasarkan hal-hal yang telah diungkapkan maka penulis terdorong untuk memaparkan suatu kasus trauma mata yang disebabkan oleh serangan hewan dengan rudapaksa ungkitan.

\section{LAPORAN KASUS}

Seorang laki-laki berusia 65 tahun datang ke unit gawat darurat RSUP Prof. Dr. R. D. Kandou Manado untuk di rawat, dikarenakan pasien terkena serangan kerbau saat sedang beristirahat di lapangan yang menopang mata kirinya. Terdapat nyeri disertai pembengkakan, pendarahan, dan penglihatan kabur empat jam sebelum masuk rumah sakit. Pemeriksaan status umum pasien dalam kondisi normal.

Pemeriksaan mata kiri menunjukkan tajam penglihatan hanya sampai lambaian tangan, motilitas okular terbatas, blefarospasm, dan laserasi lamela anterior berbentuk bulan sabit dengan keterlibatan kantal lateral (Gambar 1). Pemeriksaan segmen anterior menunjukkan perdarahan subkonjungtiva bulosa, edema kornea, dan kekeruhan berbentuk roset (rosette-shaped opacification/RSO) pada lensa. CT Scan kepala menunjukkan katarak traumatik dan perdarahan periorbital tanpa kelainan pada mata kanan (Gambar 2). Penanganan pada pasien ini dilakukan di unit gawat darurat dengan melakukan eksplorasi luka untuk menyingkirkan perforasi bola mata. Pada pasien ini dilakukan penjahitan luka lapis demi lapis pada lamela anterior, dengan menggunakan teknik penjahitan intruptus. Setiap jaringan harus diidentifikasi dengan baik untuk memastikan penyembuhan luka akan berlangsung baik (Gambar 3).

Untuk menentukan prognosis dan rencana penanganan lanjutan maka perlu dilakukan identifikasi atau perhitungan skor. Skor trauma okular (ocular trauma score/OTS) pada pasien ini ialah tiga yang menandakan kemungkinan prognosis pada visual pasien ialah $2 \%$ menjadi no light perception (NLP) dan $11 \%$ adalah menjadi Light Perception (LP) atau hand motion (HM), 15\% menjadi 1/200-19/200, 31\% menjadi $20 / 200-20 / 50$, dan $41 \%$ menjadi $>20 / 40$, dengan tajam penglihatan tetap sama, yaitu lambaian tangan, Pasien ini diobservasi dan dilakukan perawatan luka selama lima hari di rumah sakit, dan direncanakan untuk dilakukan operasi katarak pada mata kiri setelah luka penjahitan sembuh untuk rehabilitasi fungsi penglihatan.

Setelah masa pemulihan sekitar dua bulan dan luka penjahitan sembuh, pasien 
datang kontrol ke poliklinik mata RSUP Prof. Dr. R. D. Kandou Manado dan direncanakan untuk operasi katarak pada mata

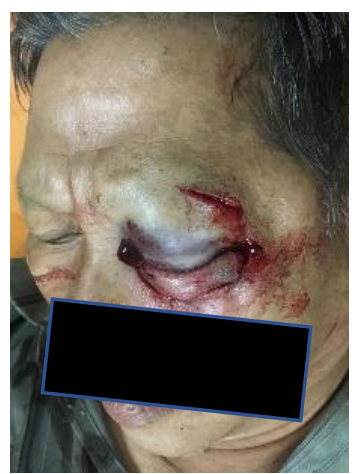

kiri. Setelah dilakukan operasi katarak pada mata kiri didapatkan tajam penglihatan mata kiri pasien 20/40.

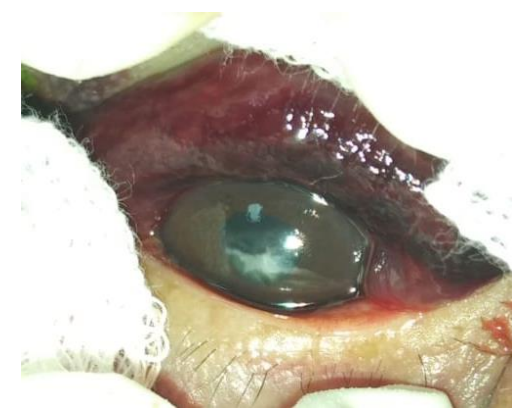

Gambar 1. Pasien saat pertama kali datang; kiri, gambar kondisi umum pasien; kanan, gambaran segmen anterior secara makroskopik

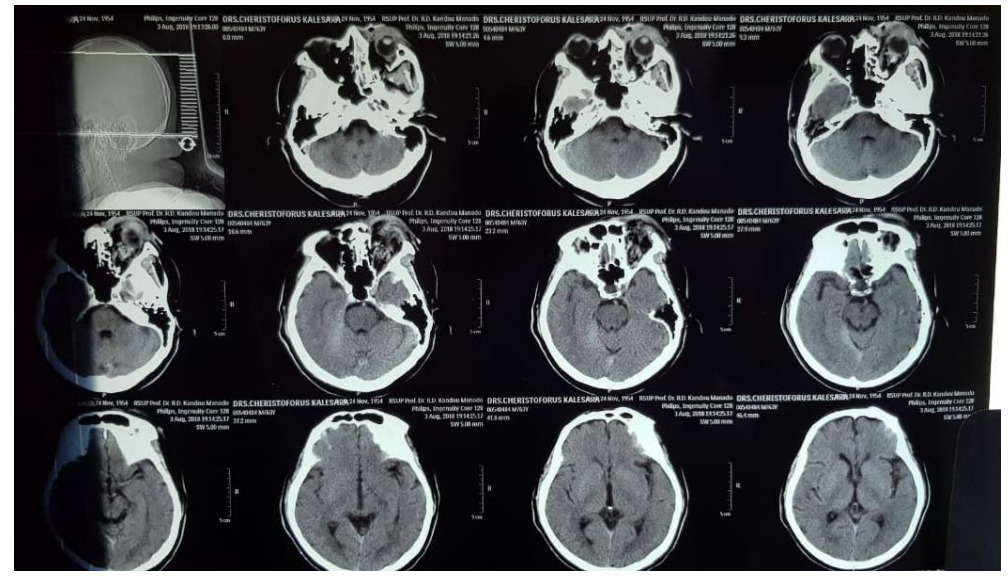

Gambar 2. Scan kepala menunjukkan katarak traumatik dan perdarahan periorbital, tanpa kelainan pada mata kanan
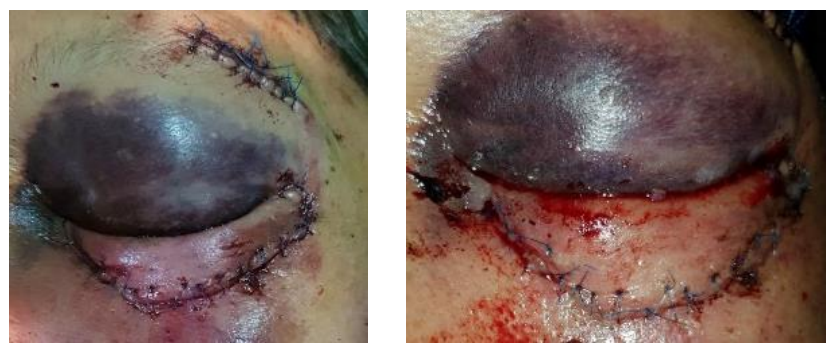

Gambar 3. Pasca penjahitan pada lamela anterior lapis demi lapis.

\section{BAHASAN}

Pada pasien ini dilaporkan adanya serangan tak terduga dari kerbau. Sekitar $39 \%$ trauma jenis ini biasanya didapatkan di lokasi tempat bekerja, dan pada pasien ini di ladang. Selain penyebab mekanis umum dari cedera mata, terdapat sejumlah objek yang tampaknya berpeluang menyebabkan trauma mekanis baik berupa benda tumpul maupun benda tajam; semuanya telah dilaporkan dalam literatur. Pada kasus ini serangan kerbau merupakan jenis serangan 
yang unik karena selain rudapaksa, kerbau juga kemungkinan besar memiliki tanduk. ${ }^{5-}$

Untuk cedera mekanis peristiwa utamanya ialah terjadinya kontak mekanis antara benda padat dan permukaan mata, biasanya berhubungan dengan kecepatan tinggi. Cedera mata mekanis yang parah dapat terjadi di hampir semua tempat yang berhubungan dengan kecepatan tinggi. Kerbau dikatakan merupakan salah satu hewan yang pergerakannya cepat, dan kekuatannya terletak pada kecepatan kerbau tersebut melakukan pengungkitan kepala dan menyerang dengan tanduknya. ${ }^{8,9}$

Berdasarkan data, pada sekitar 87,6\% kasus trauma mata dapat ditemukan hifema. Beberapa pasien juga mengalami kerusakan pada struktur bola mata lainnya, berupa iridodialisis, iridorrhexis, subluksasi atau luksasi dari lensa, hemoftalmos, edema retinal atau perdarahan, dan pecahnya koroid. Sebanyak 19,3\% kasus mengalami bola mata pecah dari total jumlah cedera tumpul. Luka memar yang diikuti pecahnya bola mata biasanya disebabkan oleh benturan dengan sebatang kayu dan tanduk sapi, atau terjadi saat terjatuh, mengenai benda yang terbuka. Pada keadaan demikian biasanya terjadi penurunan isi bola mata, yang umumnya berakhir dengan amaurosis. ${ }^{1}$ Dapat disimpulkan bahwa kecepatan dalam melakukan diagnosis scoring merupakan kunci yang sangat penting.

Penilaian OTS sudah sering digunakan pada kasus cedera mata. Demikian pula pada kasus ini, OTS juga dapat digunakan. Variabel OTS yang digunakan, yaitu ketajaman visual, ruptur, endoftalmitis, cedera perforasi, ablasi retina, dan defek pupil aferen. ${ }^{10}$ OTS juga sesuai untuk memrediksi hasil visual dari cedera tembus, cedera bola mata terbuka, dan cedera terkait senjata. Data literature menunjukkan bahwa sensitivitas penglihatan prediksi OTS di NLP, 20/20020/50, dan 20/40 sebesar 100\%. Kekhususan OTS dalam memrediksi visi di LP/HM $1 / 200-19 / 200$ ialah $100 \%,{ }^{9}$ sehingga diputuskan untuk menggunakan OTS pada situasi ini. Selain karena spesifitas dan sensitifitasnya, penilaian OTS juga dapat mendes- kripsikan kondisi pasien (Tabel 1).

Tabel 1. Metode komputasi untuk mendapatkan skor OTS ${ }^{9}$

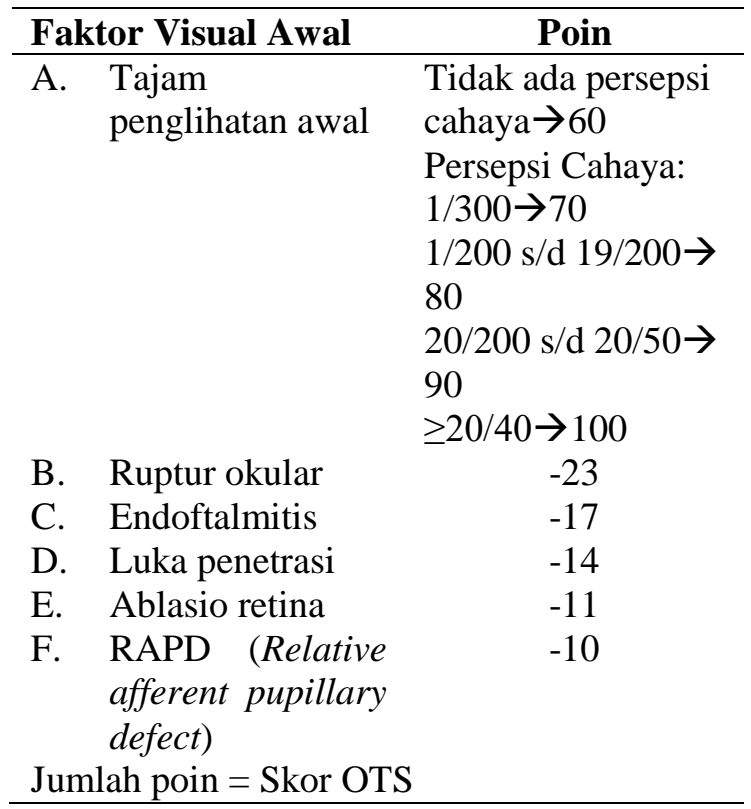

Terdapat lima faktor penting dalam prognosis hasil visual: 1) adanya perbedaan bermakna dalam ketajaman visual akhir antara pasien yang tiba di rumah sakit dalam waktu 24 jam dan yang datang 24 jam setelah cedera; 2) Cedera bola mata terbuka zona III memiliki prognosis visual yang lebih buruk daripada cedera zona I dan zona II; 3) ketajaman visual awal berkorelasi dengan ketajaman visual akhir; 4) cedera bola mata terbuka dan cedera bola mata tertutup memiliki prognosis yang berbeda; dan 5) pasien dengan skor yang lebih tinggi dan nilai OTS yang lebih tinggi memiliki penglihatan yang lebih baik. ${ }^{11-13}$ Pada kasus kompleks seperti ini, pemeriksaan anamnesis dan fisik perlu dilakukan dengan sangat teliti karena dapat memengaruhi hasil OTS.

\section{SIMPULAN}

Kasus serangan kerbau terhadap manusia memang sangat berbahaya, namun hingga saat ini belum pernah dilaporkan terkena di bagian mata. Adanya sifat paksaan dan kekuatan jungkit dari hewan tersebut perlu dievaluasi lebih lanjut. Trauma tumpul dapat menyebabkan deformitas mata dengan komplikasi, dan OTS merupakan metode yang baik dan dapat membantu dokter mata 
untuk memrediksi hasil visual dan perencanaan tindak lanjut.

\section{Konflik Kepentingan}

Penulis menyatakan tidak terdapat konflik kepentingan dalam studi ini.

\section{DAFTAR PUSTAKA}

1. Jovanović M, Stefanović I. Mechanical injuries of the eye: incidence, structure and possibilities for prevention Clinical Center of Serbia, Institute for Eye Diseases, Belgrade, Serbia. 2010. Available from: http://www.doiserbia. nb.rs/img/doi/0042-8450/2010/004284501012983J.pdf

2. Niiranen M. Perforating eye injuries. A comparative epidemiological, prognostic and socioeconomic study of patients treated in 1930-39 and 1950-59. Acta Ophthalmol. 1978;135(Suppl):1-87.

3. Gundurova RA. Injuries of the eye. In: Kopaeva VG, editor. Eye Diseases. Moscow: Meditsina, 2002; p. 468-508 (Russian).

4. Framme C, Roider J. Epidemiology of open globe injuries. Klin Monbl Augenheilkd 1999;215(5):287-93 (German).

5. Ukponmwan CU, Momoh RO. Broomstick injuries to the eye; an emerging cause of blindness among children in Nigeria. Niger J Surg. 2015;21(1):13-7.

6. Quezada-Del Cid NC, Zimmermann-Paiz MA, Ordoñez-Rivas AM. Clinical and epidemiological characteristics of ocular trauma in children under 14 years of age. Arch Argent Pediatr. 2015;113(5): e260-e263.

7. Hoskin AK, Yardley AME, Hanman K, Lam G, Mackey DA. Sports-related eye and adnexal injuries in the Western Australian paediatric population. Acta Ophthalmol. 2016;94(6):e407-e410.

8. Hoskin AK, Philip S, Dain SJ, Mackey DA. Spectacle-related eye injuries, spectacle-impact performance and eye protecttion. Clin Exp Optom. 2015;8(3):203-9.

9. Kuhn F, Maisiak R, Mann L, Mester V, Morris $\mathrm{R}$, Witherspoon CD. The ocular trauma score (OTS). Ophthalmol Clin North Am. 2002;15(2): 163-5.

10. Schorkhuber MM, Wackernagel W, Riedl R, Schneider MR, Wedrich A. Ocular trauma scores in paediatric open globe injuries. Br J Ophthalmol. 2014;98(5): 664-8.

11. Agrawal R, Wei HS, Teoh S. Prognostic factors for open globe injuries and correlation of ocular trauma score at a tertiary referral eye care centre in Singapore. Indian J Ophthalmol. 2013; 61(9): 502-6.

12. Acar U, Tok OY, Acar DE, Burcu A, Ornek F. A new ocular trauma score in pediatric penetrating eye injuries. Eye (Lond). 2011;25(3):370-4.

13. Unver YB, Kapran Z, Acar N, Altan T. Ocular trauma score in open-globe injuries. $\mathrm{J}$ Trauma. 2009;66(4):1030-2. 